\title{
Mathematics Teaching in Vietnam in the Context of Technological Advancement and the Need of Connecting to the Real World
}

\author{
Trung Tran ${ }^{1}$ \\ Vietnam Academy for Ethnic Minorities, \\ Hanoi, Vietnam \\ https://orcid.org/0000-0002-0459-7284 \\ Tien-Trung Nguyen \\ Vietnam Journal of Education, \\ Institute of Theoretical and Applied Research, Duy Tan University \\ Hanoi, Vietnam \\ https://orcid.org/0000-0002-3320-8962 \\ Thi-Phuong-Thao Trinh \\ Thai Nguyen University of Education, \\ Thai Nguyen, Vietnam \\ https://orcid.org/0000-0001-6277-4907
}

\begin{abstract}
In the context of fundamental and radical reform of education and training in Vietnam, the educational goals are changing towards students' competencies instead of knowledge and skills for students as in the past. Vietnam's mathematics curriculum is going to innovate after 2018. Mathematical education constructs the connection between mathematical ideas, between mathematics and other subjects, and between mathematics and real life. This article investigates two significant issues in mathematics teaching in Vietnam: the purpose of learning mathematics among Vietnamese pupils and mathematics teaching methods concerning reality. Based on the findings from these questions, the article proposes some recommendations for mathematics teaching regarding the methods and appropriate extent to which teachers should connect mathematics to the real world in the context of rapid science and technology development as well as the adjustments to the current mathematical content at schools. Also, this article presents some examples of exploring practical content problems and designing real-life contexts in mathematics teaching to develop students' competency in Vietnam. The researchers also suggest that Vietnam's national mathematics curriculum needs reforming to keep up with the pace of
\end{abstract}

${ }^{1}$ Corresponding author: Trung Tran, trungt1978@gmail.com 
development in the field of information and communication in the country.

Keywords: mathematics education; practical situation; mathematics teaching method; the real-life context in mathematics; Vietnam

\section{Introduction}

Mathematical education in New General Education Curriculum in Vietnam constructs and develops students' core qualities, standard capacities, and mathematical capabilities with core components: mathematical thinking and reasoning, mathematical modeling, mathematical problem-solving ability, mathematical communication ability, ability to use mathematical tools and medium; construct knowledge and skills and provide opportunities for students to experience, apply mathematics to real-life (Linh \& Phuong, 2019; Ministry of Education and Training, 2018).

The application of Realistic Mathematics Education (RME) in Vietnam was rare from its introduction in 2005 to 2010; however, following Resolution 29 in 2013, RME received extensive attention from not only the government but also the public, and teachers (Trung et al., 2020) . The Realistic Mathematics Education (RME) developed by the Freudenthal Institute is also known as "real-world mathematics education". The development of the new curriculum (Ministry of Education and Training, 2018) in general and its focus on realistic mathematics in particular promises major adjustments in Vietnamese mathematics education.

There is a great deal of research in the field of mathematics teaching that concerns the connection of mathematical knowledge to the real world for different levels, from elementary to college in Vietnam, such as (Dung, Duyen, An, Giang, \& Phuong, 2019; Nam, 2016; Nghi, 2018; Tam \& Ngu, 2017; Tong, Loc, Uyen, \& Giang, 2019; Trung, 2018; Trung, Thao, \& Trung, 2019; Vui, 2018), etc. The findings of those studies also focus on various aspects such as mathematical culture, the connection of mathematics with reality, mathematical competencies, organization of mathematics lessons to use mathematical knowledge for solving mathematical problems with useful contents or practical issues to develop and enhance learners' mathematical abilities. It is the educational approach that learning activities, must start from and directing towards reality.

Mathematics is a science that arises, develops from real life and serves as practical tools for real problems (Boyer \& Merzbach, 2011; Schubring, 2014). Therefore, mathematics teaching must be linked with the reality in society as well as in learner's life. Nevertheless, in many cases, instead of originating from real life, some mathematical knowledge derives from the creativity of mathematicians, which go beyond and hidden from reality. It's the matter of the fact that mathematics is a shared playground of those with the particular intelligence of mathematics or logic as called by Gardner in his multiple intelligence theory (Gardner \& Hatch, 1989). 
It's also necessary to state that the rapid development of science and technology has led to widespread impacts, sometimes dramatic changes in social life, which enables the application of science and technology in education, as well as emerging challenges and problems for education in the context of the explosion of science and technology. For example, the robust development of software, including mathematical software, mathematical games and education software has to lead to the opportunities to develop, apply and exploit them in mathematics teaching. Technology development entails new requirements for new personnel whose education could be contributed to mathematics.

Differently from the approach of many countries in the world, in the documents on mathematical education in Vietnam, the concept of mathematics teaching is referred to more than the concept of "mathematics learning". Putting it simply, "mathematics teaching" is a teacher's activity to organize students to perform "mathematics learning". This shows the significant focus and attention on the activities of teachers in the school during teaching and learning.

Hence, we try to answer the question: How mathematics teaching is suitable for the context of technological advancement in Vietnam and to connect to real-life? By analyzing the status and role of mathematics, the mathematics learning process and achievements, the development of science and technology, international integration in education, and studies on the relationship between general and academic mathematics, we pointed out some notes in mathematics teaching. After that, some of the teaching situations were built based on those notes and fitted into the Vietnamese context.

\section{Mathematics learning goals}

According to research on mathematics education in the world, it is necessary to aim for several objectives and to set learner's internal goals as follows: (i) Understanding the values of mathematics (meaning, application); (ii) Developing competence of doing mathematics exercises (mastering necessary skills and techniques, understanding concepts and effectively exploiting theorems, lemmas, consequences to do the exercises, etc.); (iii) communicating in mathematics and developing thinking skills (in particular mathematical thinking); (iv) understanding theories and mathematical theories to build a scientific world view and apply into practice and (v) developing general problem-solving competence, in particular, mathematical problem-solving.

Therefore, it can be seen that learning mathematics to the real world will contribute significantly in fulfilling objectives (i), (iv), (v).

Moreover, it should be noted that:

- Mathematics is a process of actively working. To learn mathematics, the first thing to do is practicing mathematical problem-solving, i.e., to solve mathematical problems and learn the techniques to solve them. Therefore, students need to be equipped with primary and minimum knowledge and sufficient skills to solve math at the general level. The general level is a level that is designated generally 
for everyone, corresponding to each level and grade (Hiebert et al., 1996; Malmia et al., 2019).

- Learning mathematics is not just learning arithmetic, algebra, geometry, and analysis. Mathematics is also presented in finance, economics, medicine, biology, sociology, etc. in life, and mathematics must be applied in those areas. Only then will mathematics become valuable, useful and attractive to many students (Barab et al., 2007; Tam \& Ngu, 2017; Vui, 2018).

- From the analysis of the status and role of mathematics, the mathematics learning process and achievements, development of science and technology, international integration in education, and studies on the relationship between general and academic mathematics, some notes in mathematics teaching can be pointed out as follows:

Firstly, mathematics teaching in the first place should focus on equipping learners with mathematical knowledge and skills such as concepts, theorems, lemmas, axioms, consequences, processes, rules, etc. The better learners master the above experience and expertise, the higher the chances they can apply them to solve mathematical problems with problem-solving skills, proving skills, etc (Björn, Aunola, \& Nurmi, 2016).

Secondly, another important goal of mathematics teaching is to develop thinking skills, especially logical thinking, dialectical thinking and creative thinking with mathematical characteristics. Therefore, mathematics teaching should focus on developing thinking (Palinussa, 2013).

Thirdly, it is necessary to effectively strengthen the connection between mathematical knowledge, ideas and the real world (social life, real-life of learners). Through exploiting practical situations to teach students the mathematical concepts and principles (such as the idea of expanding numbers sets, structural thinking in mathematics, variable thinking, continuous thinking; optimal thinking, the concept of function, or problems of connection, the interdependence between objects in nature, and society, the design of sets, etc. some essential principles such as the Dirichlet principle, discrete extremal principle, descent principle, etc.) (Nam, 2015; Viet, 2013).

Fourthly, it's advisable to enhance information technology application in mathematics teaching (Cowan, 2006; Wang, 2018), in the aim of focusing on learner' thinking skills and problem-solving skills with the use of mathematics and widespread and fundamental types of mathematical thinking as a tool at the same time calculators, computers, mathematical software, etc. are the instruments to accomplish that goal, regardless of the related discipline (within mathematics or in other areas). Therefore, information technology (calculators, computers, software, etc.) should be used more widely in the classroom, as part of learning activities rather than as a presentation tool or search engines, most of which are just by teachers (Dabbagh et al., 2016). For example, it is advisable to reduce the requirements for calculating skills that pocket calculators are now so available; consider the system of using dots "." or comma ", " in decimal numbering in Vietnam (to be in line with many countries and compatible with calculation software, such as Microsoft Excel); consider teaching students how to use 
mathematical software right at general education (typing formulas with Mathtype, drawing with Geogebra, necessary calculations with Mapple, etc.) to improve students' competence and increase the time using mathematics to solve problems.

Fifthly, consideration should be given to adjusting teaching content appropriately to ensure the interlinking with the tertiary education program. Some issues to be considered include: increasing the volume and lowering the level of statistics and probability knowledge in the program; deciding on the same rules on writing matrix, determinant (solving the linear equation in two and three variables), the coordinates of points, vectors; etc. for both the general and tertiary education programs.

\section{Teaching mathematics in relation to reality: some preliminary samples}

In the following section, we would like to present some examples of mathematical problems that can be explored in mathematics teaching in schools in a way that connects them with a practical situation to develop students' competence.

Problem 1. (for grade 4 - 5 students, from 10 to 11 years old) To prepare for the celebration of the new school year, the teacher presents students with the following problem: Each student group has half of a red A0 paper with the size $40 \times 60 \mathrm{~cm}$. Cut that A0 paper into small rectangular flags with a size of $9 \times 12 \mathrm{~cm}$ to get the most flags.

Analysis. This problem helps teachers foster, develop, and evaluate students' mathematical application competence, mathematical thinking competence, and mathematical calculation competence (written in priority order) (Ly, 2013). The problem asks students to perform an activity. To complete this activity, each group of students must fulfill two sub-activities:

+) Activity 1. Developing a method for cutting paper on a scrap paper (including two sub-activities: selecting a cutting method and then determining which plan gives more flags and most flags);

+) Activity 2. Cutting according to the plan chosen.

Some possible causes: Case 1. Students cut 20 flags; Case 2. Students cut 18 flags; Case 3. Students cut 21 flags; Case 4 . Students cut 17 flags. In which, cases 1, 2, 3, 4 correspond to Figures 1, 2, 3, 4 below.

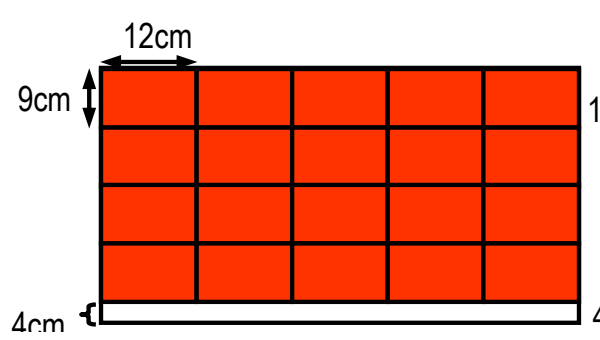

Figure 1: Students cut 20 flags

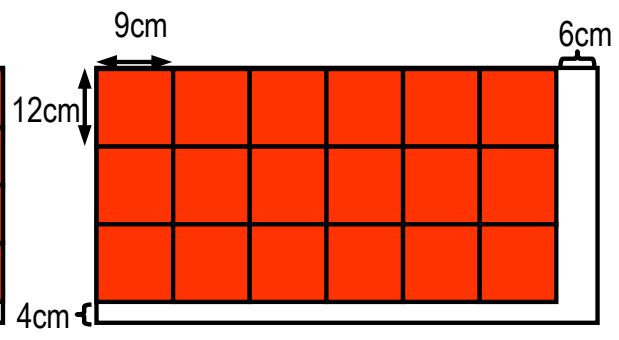

Figure 2: Students cut 18 flags 


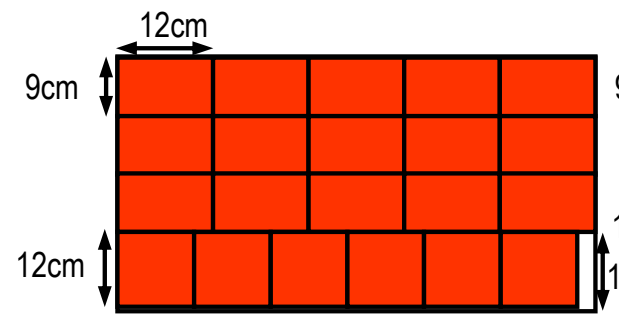

Figure 3: Students cut 21 flags

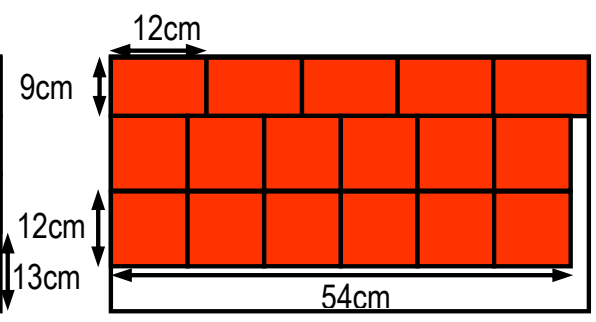

Figure 4: Students cut 17 flags

When asking groups of students to tell their number of cut flags and how to do it, teachers can encourage students to argue and cooperate in brainstorming and finding the optimal solution (a most significant number of flags). Sometimes that option can also be raised from Case 2, with only 18 flags.

Note that students may also propose different options, but the option presented in Figure 3 is the best one (cut the most flags). The most critical matter is the way the teacher creates the opportunities for students to debate and analyze, push it toward the dissatisfaction with the two cutting options shown in figure 1 and figure 2. For example, the teacher can compare the total areas of small rectangular flags in the options shown in Figure 1 and Figure 2 with the area of the given paper: The more significant number minus, the lower number is an area which is higher than $108 \mathrm{~cm}^{2}$, more substantial than a small rectangle flag! Is there any chance of saving paper more? etc. Also, it is advisable to instruct students to determine the maximum number of cut flags by dividing the area of the given paper by the space of a small rectangular flag. Specifically, we have a division with the remainder $(40 \times 64): 108=22$ (rest of 24 ), so we can cut up to 22 flags.

Moreover, it should be noted that despite such a maximum amount of banners, we cannot cut to have the maximum number as calculated! So there is a gap between the calculated and real life. In this sample, mathematical thinking provides students with optimal thinking presented as a way of working and economic thought in real life.

Problem 2. (for grade 4 - 5 students, from 10 to 11 years old) A coffee shop owner needs to replace the glass for all of his coffee tables. His shop has 12 round coffee tables, each with a diameter of $1.2 \mathrm{~m}$. The best quotations he gets from some companies are as follows

a) For the most economical option, what kind of glass will you advise to the coffee shop owner?

b) With the selected option, how much does the coffee shop owner pay? 
Table 1. Quotations of glass for a table, division wall from Window Vietnam Investment Limited Company

\begin{tabular}{|c|l|c|c|}
\hline No. & \multicolumn{1}{|c|}{ Product specification } & Unit & Unit price \\
\hline 1 & Ordinary glass 10 mm - Viet Nhat & $\mathrm{m}^{2}$ & 380,000 \\
\hline 2 & Ordinary glass 12 mm - Viet Nhat & $\mathrm{m}^{2}$ & 490,000 \\
\hline 3 & White clear tempered glass 8 mm - Viet Nhat & $\mathrm{m}^{2}$ & 580,000 \\
\hline 4 & White clear tempered glass 10 mm - Viet Nhat & $\mathrm{m}^{2}$ & 650,000 \\
\hline 5 & White clear tempered glass 12 mm - Viet Nhat & $\mathrm{m}^{2}$ & 680,000 \\
\hline 6 & White transparent laminated glass 10.38 mm (division & $\mathrm{m}^{2}$ & 650,000 \\
\hline 7 & White transparent laminated glass 12.38 mm (division & $\mathrm{m}^{2}$ & 720,000 \\
\hline
\end{tabular}

(Notes: This price already includes cutting and shipping fees within Hanoi city and VAT)

Analysis. This problem helps teachers foster, develop and evaluate students' competence of processing mathematical information, applying mathematics to practical situations, mathematical thinking and mathematical calculation (written in priority order). The problem asks the student to fulfill two sub-activities. To complete these activities, each group of students must perform two sub-activities: +) Activity 1. Selecting the type of glass: Students can choose one of two options, line 2 and line 5 (requires $12 \mathrm{~mm}$ lens), however, if students read carefully, they will see only the option inline 5 is appropriate (because of the tempered glass necessity); +) Activity 2. Determining the investment cost of the coffee shop owner.

Teachers can evaluate the competence of students through the results of activities 1 and 2. For example, inactivity 1 , if the student cannot identify correctly, it shows that not all requirements in the problem are carefully examined. Inactivity 2, students must determine the area of each table to determine the total area of 10 tables and find out the total cost for cutting glass. In this second activity, many students may make mistakes that can only be seen in the practical situation rather than in the book, as follows:

The area of a table is: $3.14 \times 0.6 \times 0.6=1.1304 \mathrm{~m}^{2}$

The area of 10 tables is: $10 \times 1.1304=11.304 \mathrm{~m}^{2}$.

The total cost (total expenses) is (if selecting the option inline 5):

$680000 \times 11.304=7686720$ (VND)

However, it is necessary to bear in mind that the company cuts the glass and charges as in figure 5:

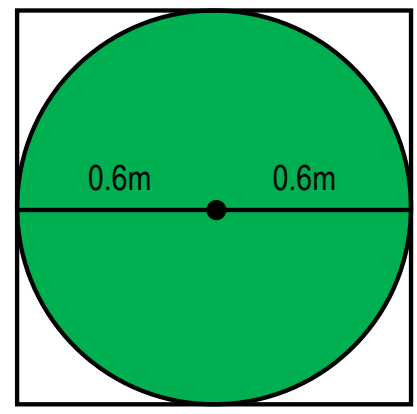

Figure 5: the way the company cuts the glass and charges 
In other words, the buyer must pay for the area of cut glass and the unusable, leftover part (the white part in Figure 5). Therefore, the cost should be calculated as follows:

The area of a table is: $1.2 \times 1.2=1.44 \mathrm{~m}^{2}$

The area of 10 tables is: $10 \times 1.44=14.4 \mathrm{~m}^{2}$.

The total cost (total expenses) is (if selecting the option inline 5):

$680000 \times 14.4=9792000$ (VND)

This is a practical problem that students, parents or close relatives may encounter in life. To solve it, it is necessary to understand the reality, the solution to the problem in real life to be able to apply mathematical knowledge in the problemsolving process (herein it is how the glass company charges the buyer). Mathematical thinking in this problem is the optimal thinking, what to apply in life is to save, think, act and work economically. At the same time, students should be reminded to apply the knowledge they have learned following reality, in the way of practice, not just as in theories and books.

Problem 3. Next, the teacher can introduce the grade 10 students (16-year-old students) a mathematical problem that can be solved and modeled with knowledge of functions and graphs of linear and quadratic functions. This is a problem related to economic issues with some new concepts to students. Mathematical knowledge is not too complicated for students to approach and understand. However, we need to explain some concepts here. First of all, we have the concept of a demand function (the function that determines the correlation of the goods demand to the price of a product), its graph is called the demand curve. For example, we can understand through the following example: By researching the market for the same type of bike, we find that the demand function for that type of bike is in the form: Units Sold $=70000-200 \mathrm{P}$ (whereas, $\mathrm{P}$ is the price or cost) of the bike, unit is in dollars (USD). We can understand better through the "demand curve" graph as follows:

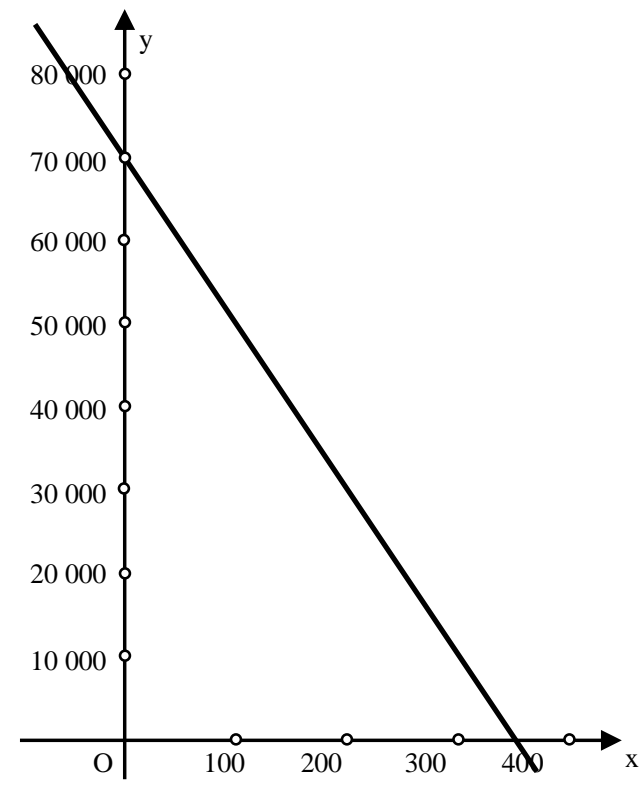

Figure 6: "demand curve" graph 
From the above demand curve, it is possible to evaluate the price of the product. For example, we cannot set prices too high, because if the item's price is too high, no one will buy them and of course all manufacturers need to calculate the highest price that can satisfy the most number of subjects, i.e., sell the most goods to bring the highest profit.

For example: According to the demand function, no manufacturer wants to sell a bike for 0 USD, but if you sell for 350 USD then no one will buy it; if sold for 310 USD, the estimated number of the bike to be sold will be 8,000 bikes.

Now we will solve the following problem of helping a small business start building its product and brand: a new type of bike. Assuming that the business produces a new bike, according to market research, the graph showing the correlation (demand function) between the price and sales is as above. At the same time, we have the following information:

1) The total amount to spend on designing and advertising products is 700 000USD,

2) The cost of producing a bike is 110USD

Helping the business determine the price of the bike (the best price) so that it can sell with the highest profit. Note that we have the formula: Profit $(P)=$ Sales $(S)$ Cost (C).

From there, the teacher can organize some activities as follows:

Activity 1: Students do the calculation using the formula P $=\mathrm{S}-\mathrm{C}$.

The expected result can be made according to these steps:

$\square$ Number of bikes sold: $70000-200 x, x$ is the selling price of a bike

$\square$ Sales $=$ Number of bikes sold with the cost of $x$

$$
=(70000-200 x) x=70000 x-200 x^{2}
$$

$\square$ Cost $=700000+110(70000-200 x) \quad=8400000-22000 x$

So, we have:

$\mathrm{P}=\mathrm{S}-\mathrm{C}=70000 x-200 x^{2}-(8400000-22000 x)=-200 x^{2}+92000 x-8400000$

Therefore, we see that the profit of the production process depends on determining the $x$-price of the product. If $\mathrm{x}$ is a variable, we have the profit function as follows:

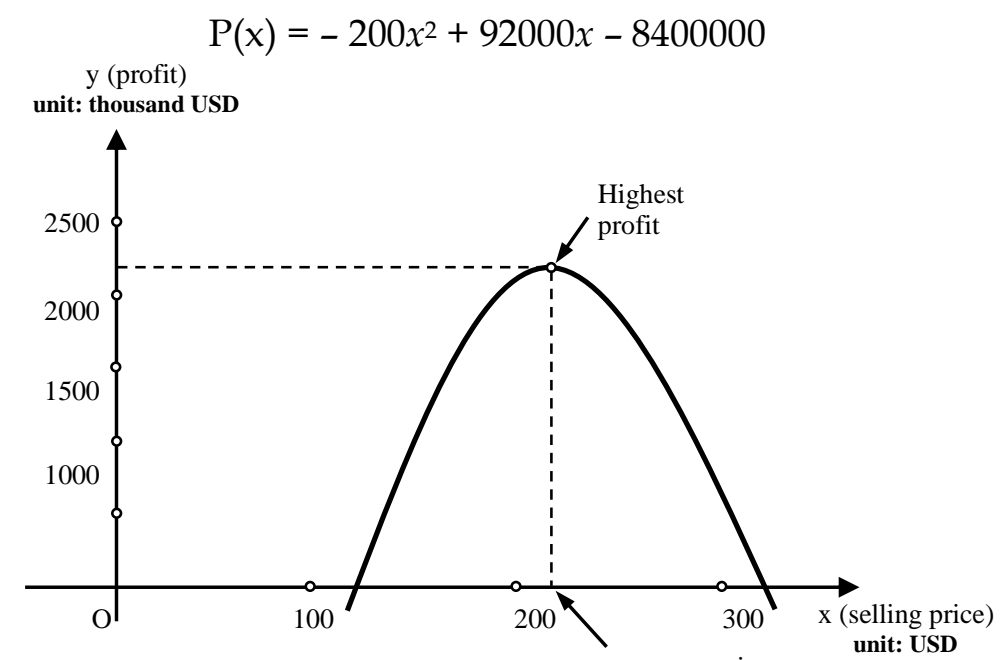

Figure 7: the $L(x)$ function graph ${ }^{\text {price }}$ 
Considering the $L(x)$ function graph as shown below (Students can draw function graph or use online graphing software, or some simple graphing software to draw graph).

From the function graph, we can conclude that the proposed selling price for the product should be: around 230 USD, of which the profit will be $\mathrm{L}(230)=2180000$ USD.

Note that the teacher can instruct the student to divide the right side of $\mathrm{L}(\mathrm{x})$ by 200 so that the calculating of $\operatorname{L} 1(x)=-x^{2}+460 x+42000$ functions to be simpler and more convenient.

Through this problem, students are introduced to some concepts related to the business such as product pricing, cost, and profit determination, demand function, knowledge of the dependence of market prices on product price and of product price on sales volume, etc.; the students have the opportunity to explore and build a function by themselves from the original knowledge and information, to use the function graph to solve a practical problem, etc. Students can apply mathematics in an exciting and real situation. They can deeply understand the concept of a function and the maximum and minimum values of a function to use them in real life. Students will see the effectiveness, practicality of mathematics and find that mathematics is closer to life.

\section{Program Analysis and learning situation construction for students}

\subsection{Some approaches of Sine theorem in triangles}

Sine theorem in triangle states that: "In an $A B C$ triangle with $B C=a, C A=b, A B$ $=\mathrm{c}$, and $\mathrm{R}$ is the radius of the circumscribed circle, we have $\frac{\mathrm{a}}{\sin \mathrm{A}}=\frac{\mathrm{b}}{\sin \mathrm{B}}=\frac{\mathrm{c}}{\sin \mathrm{C}}=2 \mathrm{R}$ " (Hao, Hy, Doanh, \& Huyen, 2006; Quynh, Cuong, Khue, \& Nghi, 2014)

A theorem is a tool for "solving triangles": Find an element of a triangle when you know sufficient factors: length of three edges; length of two sides and one angle; two angles and one side.

It is possible to analyze and point out two approaches to this theorem:

Firstly, in any $A B C$ triangle with $B C=a, C A=b, A B=c$, we have $\frac{a}{\sin A}=\frac{b}{\sin B}=\frac{c}{\sin C}$ $(*)$.

Secondly, in any $A B C$ triangle with $B C=a, C A=b, A B=c$, and $R$ is the radius of the circumscribed circle, we have $\frac{\mathrm{a}}{\sin \mathrm{A}}=2 \mathrm{R} ; \frac{\mathrm{b}}{\sin \mathrm{B}}=2 \mathrm{R} ; \frac{\mathrm{c}}{\sin \mathrm{C}}=2 \mathrm{R}$.

Thus, in the first approach, the theorem content may not involve the limited circle with a triangle, and in the second approach, it is related to the circumscribed circle 
with a triangle. It's also important to note that, in the textbook, there are two examples (in Hao et al., 2006) about the application of sine theorem in a triangle, both of which do not involve the circumscribed circle. In the proof, however, the textbook presents the second approach, i.e., it is proved that $\frac{a}{\sin \mathrm{A}}=2 \mathrm{R}$.

\subsection{Some samples of teaching situations of sine theorem in the triangle according} to the presented method to develop learners' competences

From the above methods, we design three different teaching situations, which help the students construct the sine theorem in the triangle, and present the summary as follows.

Teaching situation 1: (applying the first approach): Given the practical problem as follows:

Activity 1. The teacher asks students to discuss and explain how engineers measure the height of the Hanoi flagpole, Vietnam.

Contents: Engineers' method: Use the goniometer, at point $A$, determine the angle $\mathrm{A}=30^{\circ}$; at point $\mathrm{B}$ the corner $\mathrm{CBH}=45^{\circ}$; segment $\mathrm{AB}=29.3 \mathrm{~m}$; then, determine the height of Hanoi flagpole. Please explain how they measure it and calculate the height of Hanoi flagpole in metres?

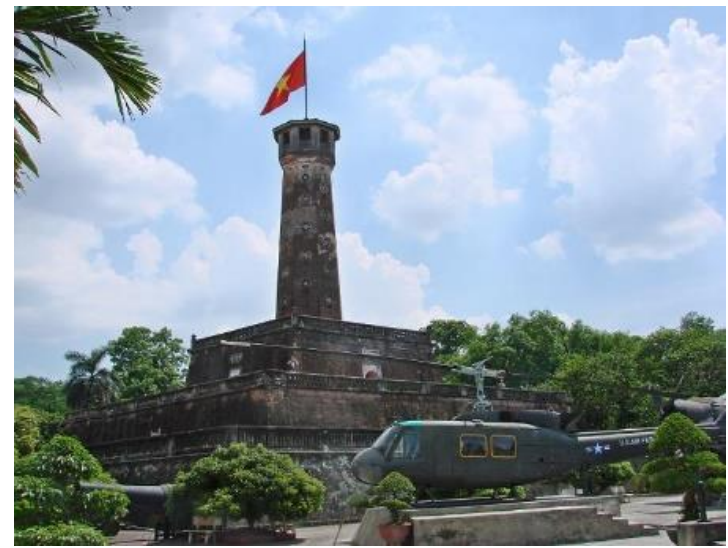

Figure 8: Hanoi flagpole, Vietnam

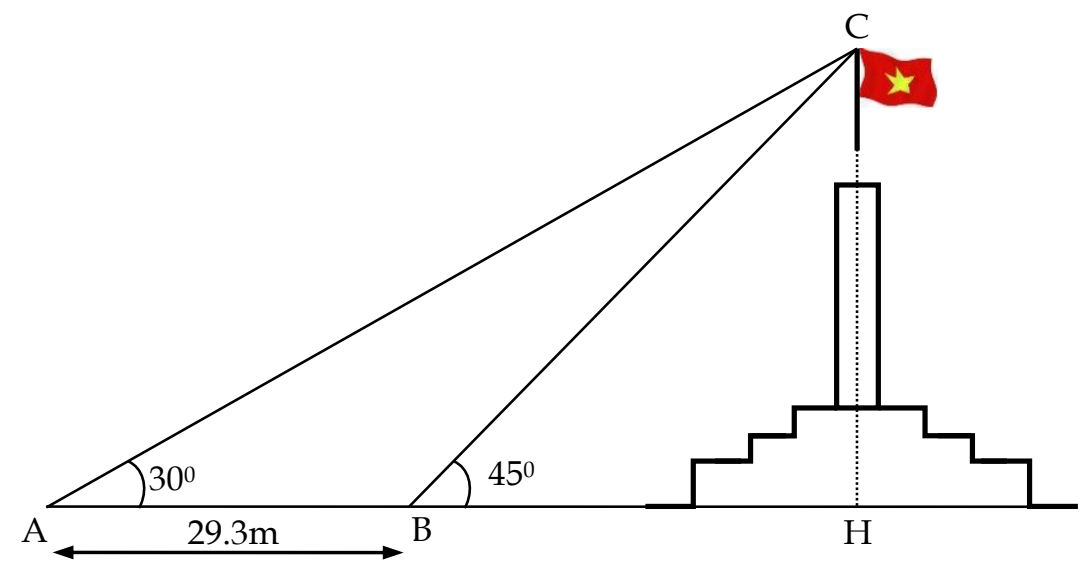

Figure 9: Description of how to measure the height of Hanoi flagpole 
Using the hypothesis of the problem, the students calculate the height $\mathrm{CH}=\mathrm{h}$ as follows: $\mathrm{h}=\mathrm{BC} \sin 45^{\circ} ; \mathrm{h}=\mathrm{AC} \sin 30^{\circ}$

Finding out $\mathrm{BC} \sin 45^{\circ}=\mathrm{AC} \sin 30^{\circ} \Leftrightarrow \mathrm{a} \sin 45^{\circ}=\mathrm{b} \sin 30^{\circ}$

$$
\Leftrightarrow \frac{\mathrm{a}}{\sin 30^{\circ}}=\frac{\mathrm{b}}{\sin 45^{\circ}}
$$

Giving that, $\sin 45^{\circ}=\sin \mathrm{B}$ so (2) becomes: $\frac{a}{\sin \mathrm{A}}=\frac{\mathrm{b}}{\sin \mathrm{B}}$ (3).

The next issue is how to exploit the third hypothesis. There are two ways to do this: - The first way, students can apply the same steps (because the role of A, B, $C$ as well as $a, b, c$ are similar) they will have $\frac{a}{\sin A}=\frac{c}{\sin C} ; \frac{b}{\sin B}=\frac{c}{\sin C}$, i.e. there will be $\left(^{*}\right)$. - The second way: students may add altitude $\mathrm{BH}_{1}$, deduce $\frac{\mathrm{b}}{\sin \mathrm{B}}=\frac{\mathrm{c}}{\sin \mathrm{C}}$ (just like the above way), and so there $\left(^{*}\right)$. Because they already know the value of angle $C$ (from the hypothesis inferred), know c (assumption), they should see the $\operatorname{cost} \frac{c}{\sin C}$. Then calculate $a($ or $b)$ and thus calculate the height $h$.

At this point, the students discover an exciting property (rule), described by $\left({ }^{*}\right)$, through a particular case.

Activity 2. Organizing events for students to speak up and prove the theorem. The teacher asks students to express the (theorem) properties by words, formulas (in the form of a guess) and ask students to prove their guesses. Students will use the same way as the case of the two angles A and B given above in the general case to prove their guesses

Teaching Situation 2 (applying the second approach): There are two ways of the organization to construct the theorem for students which can be summarized as follows (demonstration activities can be presented in the same way as in Hao et al., 2006) but still by the process of reasoning, constructing below):

Method 1. Activity 1. Motivating the constructing mechanism of the theorem.

The teacher asks students to do the task and answer the question: Giving circle (C) with center I, radius $\mathrm{R}$ and point $\mathrm{A}$ fixed (Figure 10). Using perpendicular to draw two right triangles at $A$, inscribed circle $A B C, A B_{1} C_{1}$ (Figure 11). Commenting on the length of $\mathrm{BC}, \mathrm{B}_{1} \mathrm{C}_{1}$ and explaining

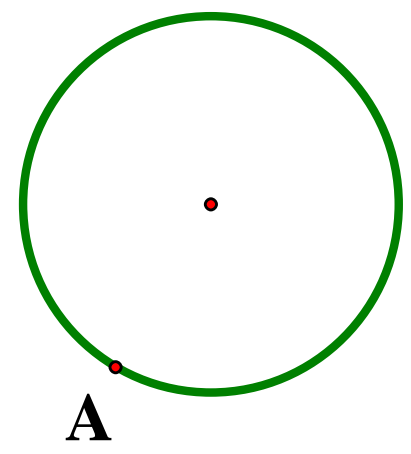

Figure 10

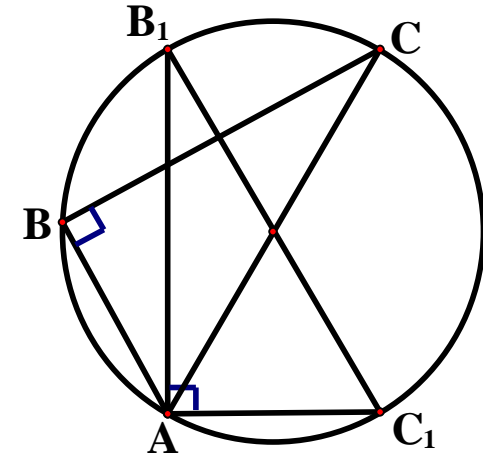

Figure 11 
Teacher: If angle $\mathrm{A}$ is not square, are $\mathrm{BC}$ and $\mathrm{B}_{1} \mathrm{C}_{1}$ equal?

Students: Please refer to some specific and individual cases.

Teacher: Dividing the class into four groups; each group solves one exercise in a handout with the content described below:

\section{HANDOUT 1 (similar to, 2, 3, 4)}

Giving circle $(\mathrm{C})$ with center I, radius $\mathrm{R}$ and fixed point A. From A we draw the triangles $A B C, A B_{1} C_{1}$ with the angle $A$ equal to $30^{\circ}$ (similar to, $60^{\circ}, 120^{\circ}, 135^{\circ}$ ) as shown in Figure 12a (related to Fig. 12b, 12c, 12d). Comparing the lengths of BC, $\mathrm{B}_{1} \mathrm{C}_{1}$ and explaining.
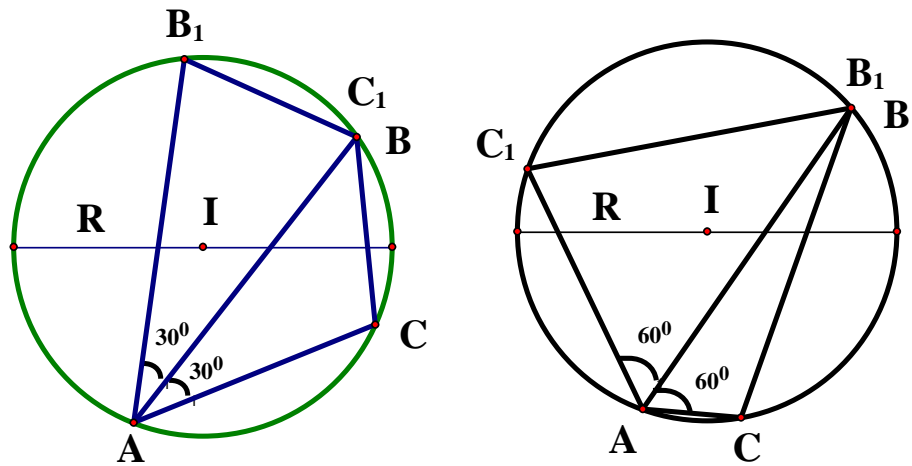

Figure 12a

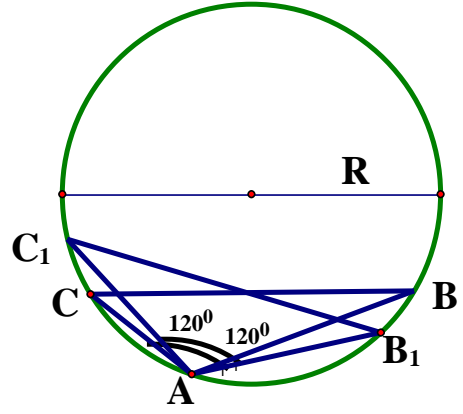

Figure 12c

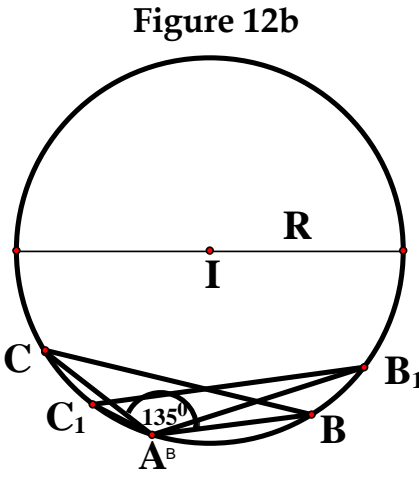

Figure 12d

It's easy for students to conclude that: $B_{1} C_{1}=B C$ and $B_{1} C_{1}$ depends on the angle $\mathrm{A}$, to be more specific, its length increases when angle $\mathrm{A} A$ increases within the range $\left(0 ; 90^{\circ}\right)$; the longest is $2 \mathrm{R}$, when $\mathrm{A}=90^{\circ}$; decreases when $\mathrm{A}$ increases within the range of $\left(90^{\circ} ; 180^{\circ}\right)$. Compared to the table of trigonometric value of unusual angles (Hao et al., 2006, p. 37), students may reflect and predict that BC has some connection with $2 \mathrm{R}$ and sine $\mathrm{A}$.

Activity 2. Construction of theorem

The teacher suggests that students transform the given exercise situations to the known task situation of the right triangle case (as shown in (Hao et al., 2006, p. 51)).

Students draw figures, put on known cases (Activity 1) and detect:

$$
\mathrm{B}_{1} \mathrm{C}_{1}=2 \mathrm{R} \sin 30^{\circ} \text { or } \mathrm{a}=2 \mathrm{R} \sin 30^{\circ} \text { (Figure } 12 \mathrm{a} \text { ) }
$$




$$
\begin{aligned}
& \mathrm{B}_{1} \mathrm{C}_{1}=2 \mathrm{R} \sin 60^{\circ} \text { or } \mathrm{a}=2 \mathrm{R} \sin 60^{\circ} \quad \text { (Figure } 12 \mathrm{~b} \text { ) } \\
& \mathrm{B}_{1} \mathrm{C}_{1}=2 \mathrm{R} \sin 120^{\circ} \text { or } \mathrm{a}=2 \mathrm{R} \sin 120^{\circ} \quad \text { (Figure } 12 \mathrm{c} \text { ) } \\
& \mathrm{B}_{1} \mathrm{C}_{1}=2 \mathrm{R} \sin 135^{\circ} \text { or } \mathrm{a}=2 \mathrm{R} \sin 135^{\circ} \text { (Figure } 12 \mathrm{~d} \text { ) }
\end{aligned}
$$

The teacher asks the students to comment on each case, the task (drawing the figure with the facts of acute and obtuse angle A), and make a judgment in the general case.

Proposal of students: In the general case, $\mathrm{a}=2 \mathrm{R} \sin \mathrm{A}$ and similarly, $\mathrm{b}=2 \mathrm{R} \sin \mathrm{B}, \mathrm{c}=2 \mathrm{R} \sin \mathrm{C}$. Accordingly, resulting in the same ratio, stated in the form of $\left(^{*}\right)$.

Method 2. Activity 1. Creating motivation for theoretic construction.

The teacher will let students work in groups to answer the following questions: Give circle $(C)$ with center $I$, radius $R$ and fixed point $A$. From $A$, draw the triangles $\mathrm{ABC}\left(\mathrm{B}, \mathrm{C}\right.$ lie on the circle) with angles $\mathrm{A}$ of $30^{\circ}, 60^{\circ}, 90^{\circ}, 120^{\circ}, 135^{\circ}$ in the same figure. In what case is $\mathrm{BC}$ the longest? Why? Comment on the changes of $\mathrm{BC}$ length when angle A changes? Can you predict the dependence of $\mathrm{BC}$ on angle $\mathrm{A}$ or trigonometric values of angle A?

Students can easily conclude that: $B_{1} C_{1}=B C$ and $B_{1} C_{1}$ depends on the angle $A$, specifically, its length increases when angle $A$ increases within the range of $(0$; $\left.90^{\circ}\right)$; the largest value is $2 \mathrm{R}$, when $\mathrm{A}=90^{\circ}$; its length decreases when $\mathrm{A}$ increases within the range of $\left(90^{\circ} ; 180^{\circ}\right)$. (Figure 13)

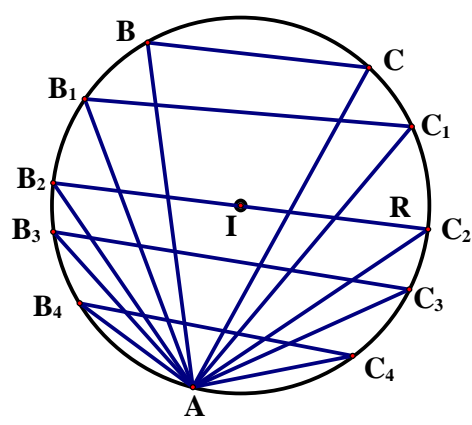

Figure 13

Compared to the table of trigonometric value of unusual angles (Hao et al., 2006, p. 37), students may reflect and predict that $B C$ has some connection with $2 \mathrm{R}$ and sine A.

Activity 2. Construction of theorem (similar to Activity 2, shown in Method 1). 


\section{Relationship between information technology and mathematics teaching in schools}

First of all, starting from several practical problems, the teacher organizes activities for students to solve them in different ways and means.

Problem 5. Let's consider a situation in football - Direct free kick situation: Assuming that the positions of the ball $\mathrm{M}_{0}, \mathrm{M}_{1}, \mathrm{M}_{2}$ (figure 14) and the goalkeeper only runs on the vertical line, on segment $\mathrm{AB}$.

a) In your opinion, which position should the goalkeeper choose in order not to make position mistakes? Explain your choice.

b) Considering the cases in the Video (some videos: https://www.youtube.com/watch?v=Y_QvpF84TZc) and identify the goalkeeper who made a mistake and who didn't? Compare the video with the results of calculation and comment!

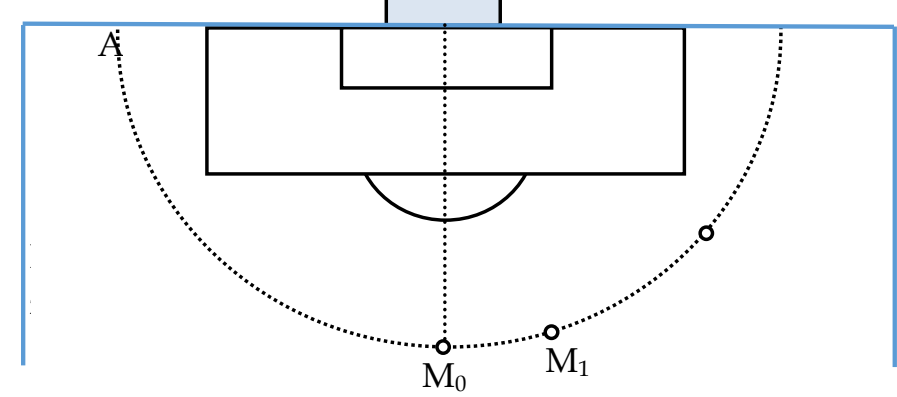

Figure 14: Modeling the direct free kick situation

Analysis. Students need to use the knowledge of geometry (angle, bisector, etc.), the real-life knowledge of football (shot angle, ball speed, defending and corner closing ability, etc.). Theoretically, if the free kick is placed at the position $\mathrm{M}_{0}$, the goalkeeper should stand in the middle of the goal. If the free kick is placed at position $\mathrm{M}_{1}$ (similar to $\mathrm{M}_{2}$ ), the goalkeeper should stand at position $\mathrm{P}_{1}$ so as not to make position mistake, because $\mathrm{P}_{1}$ is the foot of the bisector of the corner $\mathrm{AM}_{1} \mathrm{~B}$ on the edge $A B$ (similarly, The goalkeeper should be at position $\mathrm{P}_{2}$ so as not to make position mistake because $\mathrm{P}_{2}$ is the foot of the bisector of the $\mathrm{AM}_{2} \mathrm{~B}$ on the edge $A B)$. In Figure 15, it can be seen that $l_{1}>l_{2}$, so $t_{1}>t_{2}\left(t_{1}, t_{2}\right.$ is the time for the ball to move from the free kick position to the goal, in the same shooting condition). In this example, if students use the software, the problem can be solved more smoothly. Furthermore, as discussed above, the calculation of numbers is not necessary here. Students must find the way, the tools, and steps to solve the problem. The estimate by using some additions, subtractions, multiplications, graphing, etc. can be done by a computer. 


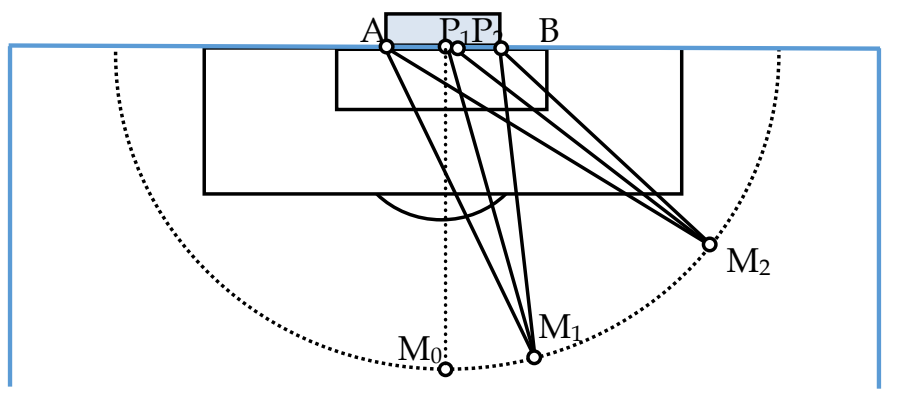

Figure 15: The position of the free-kick

When analyzing the video, it's the fact that when catching the ball, the goalkeeper tends to stand to the right of the shot but not in the position of the foot of the bisector as calculated. Thus, students need to have appropriate explanations, based on understanding and learning about football and even mathematical analysis.

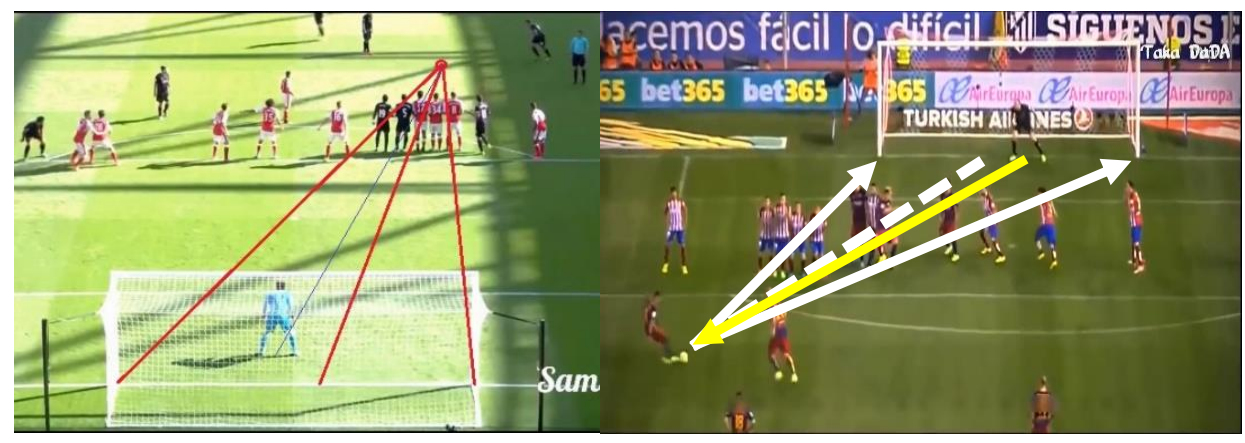

Figure 16: Free kick situation are cut out from the video

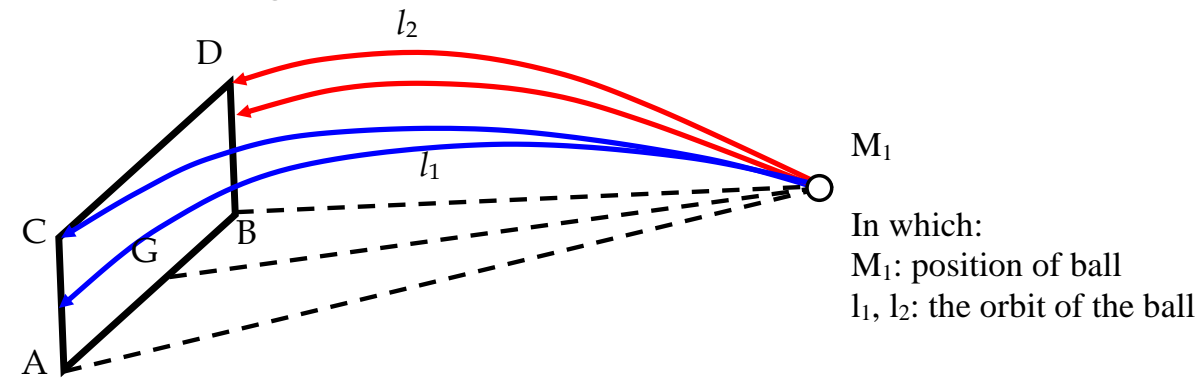

Figure 17

Problem 6. Continuing to consider a free kick situation in problem 4. Usually, the free kick position is M1; then, the barrier will be as shown in Fig. 18. Some initial information is as follows: The distance between the setpoint and the wall is 9,15m; the wooden frame height is $2.44 \mathrm{~m}$, the wooden frame width is $7.21 \mathrm{~m}$, the maximum height of the players at the wall is $1.8 \mathrm{~m}$, the highest jump ability to block the ball is $0.4 \mathrm{~m}$, the distance from the setpoint to point $B$ is $23 \mathrm{~m}$. Supposing that the player kicked in angle B, the shot was over the barrier. Calculating the angle between the ball and the ground when the ball leaves the field at the time of kicking? Students may use software and pocket calculators. 

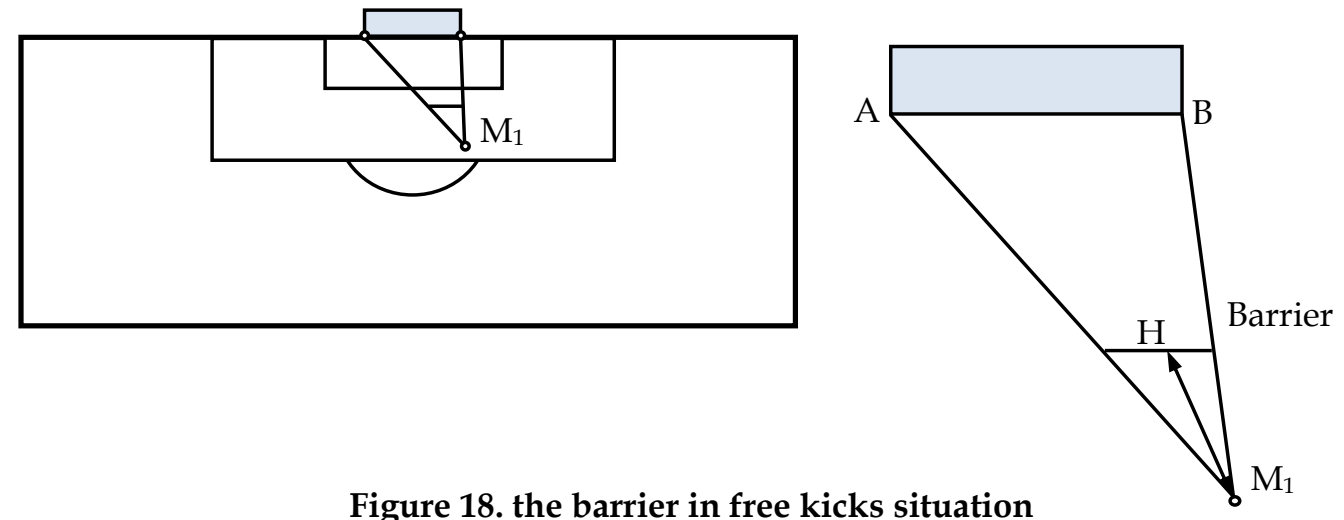

Figure 18. the barrier in free kicks situation

Analysis. This problem helps teachers develop or evaluate students' modeling competencies. One note is that, when organizing students to work in a group to solve a problem, teachers need to guide them to focus on problem-solving, using free online software applications to support them in finding the results and avoid spending too much time on solving equations, the system of equations, etc.

Supposing that you can describe the path of the ball from the setpoint to the corner of the goal as shown below:

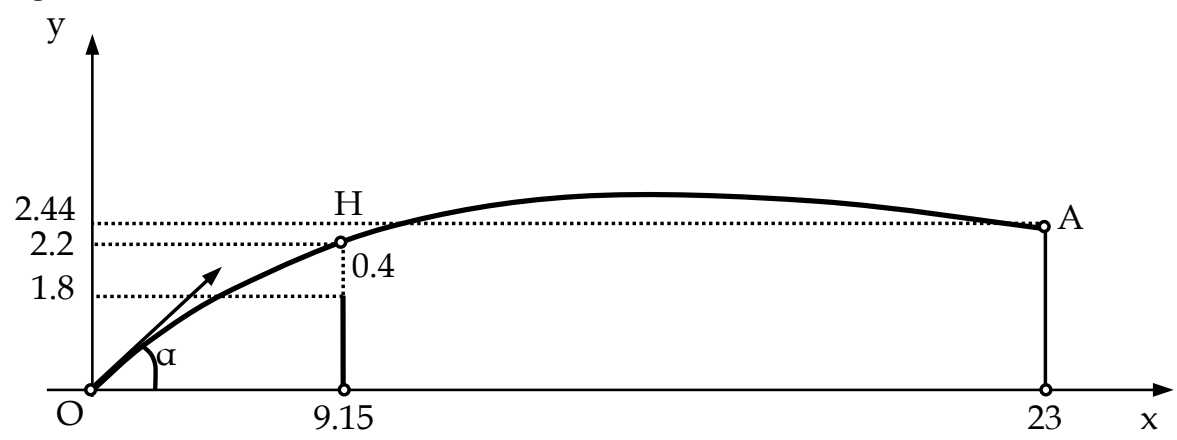

Figure 19. The path of the ball from the setpoint to the corner of the goal

The teacher should instruct students to perform several tasks: establishing the curve equation; calculating the angle of the ball to the ground; trying drawing the graph after forming the equation (on software), etc. Through the depiction, the teacher can instruct students to recognize the curve of the ball movement as a parabola. From there, the students have the direction to build and find that equation.

The parabolic demonstrating function is quadratic $y=f(x)=a x^{2}+b x+c(a, b, c \in R, a \neq 0)$. On the demonstrating line of the curved motion of the ball, we identify 3 points: $\mathrm{O}(0 ; 0) ; \mathrm{H}(9.15 ; 2.2) ; \mathrm{A}(23 ; 2.44)$. So we have two systems of equations:

$$
\left\{\begin{array}{l}
(9.15)^{2} a+9.15 b=2.2 \\
23^{2} a+23 b=2.44
\end{array}\right. \text {. }
$$

Performing equation solving by Quickmath software (online, free) we can find two co-efficient $a$, $b$ of function $f(x)$ : 
Quickmath step-by-step math solver

Expression Equation Inequality contact us

Solve Graph System

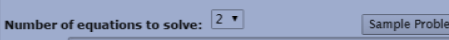

Equ. $=1:=(9.15)^{\wedge} 2 a+9.15 b=2.2$

$(9.15)^{2} a+9.15 b-2.2$

Equ. \#2: $23 \wedge 2 a+23 b=2.44$

$23^{2} a+23 b=2.44$

Solve for: $a, b \quad$ Auto Fill

$\left\{(9.15)^{2} a+9.15 b=2.2\right.$

$\left\{23^{2} \cdot a+23 b=2.44\right.$
$\{83.7225 a+9.15 b=2.2$

$\left\{23^{2} \cdot a+23 b=2.44\right.$

$\{(83.7225 a+9.15 b)+(-9.15 b)=2.2+(-9.15 t$

$\left\{23^{2} \cdot a+23 b=2.44\right.$

Result:

$\{a=-0.00970037565$

$\left\{\begin{array}{l}a=0.329195595 \\ b=0\end{array}\right.$

Figure 20. Using quick math software to solving the equation

So the function we need to find is: $y=f(x)=-0.00970037565 x^{2}+0.329195595 x$. The curve line demonstrates the motion of the ball (drawn with the Graph software):

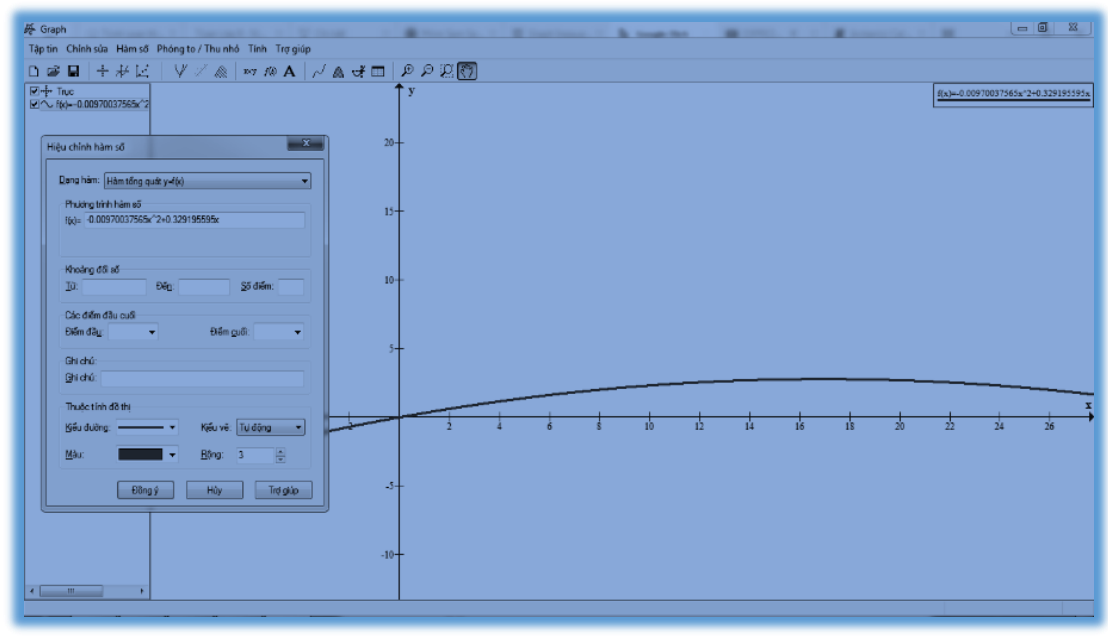

Figure 21. Drawing function graph with the Graph software

Thus, the angle of the ball to the ground is $\alpha=\arctan (0.329195595)$. Using the online software below, we conclude that the angle to kick the ball is over $18^{0}$ : 


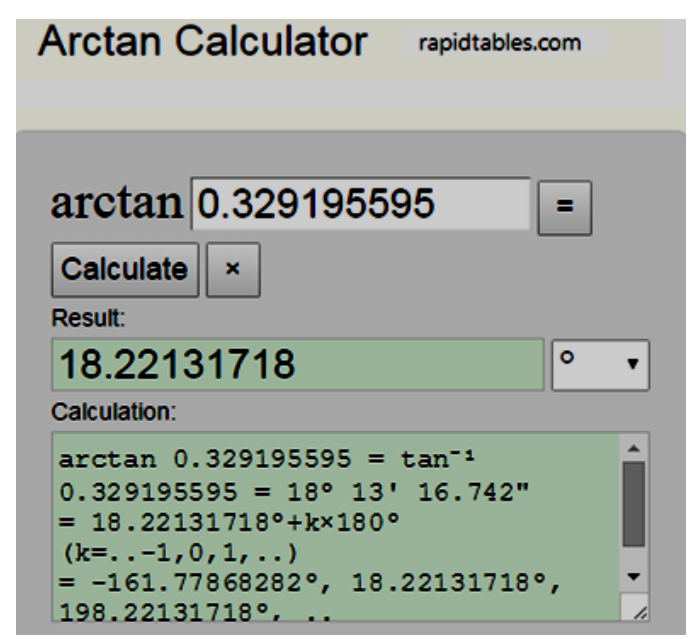

Figure 22: Using the online software to calculate the angle

With the organization of teaching activities through the abovementioned examples and sequence, students perform the activities in a similar way to thinking function: identifying the correspondence; setting correspondences (through the expression of the first or second-class function); exploiting the correspondences (using the knowledge of functions to solve the problem and apply in practice).

\section{Conclusion}

This research initially contributes to the stage of reviewing and adjusting the content of teaching mathematics in high schools in Vietnam. At the same time, research has also attempted to clarify the levels and methods of teaching mathematics concerning real life to an appropriate extent. The authors also highlight the need to avoid teaching pure mathematics with complicated manipulations, which is not suitable for the majority of students. However, it is also crucial to prevent overgeneralization that teaching mathematics should always be concerning real life. It is advisable that mathematics teaching is focusing on developing learners' competencies to solves problems related to mathematics and logical and scientific thinking. The proposed samples serve as the researchers' recommendations for the design, development, and publication of general mathematics curriculum in schools in Vietnam in the context of international integration, the radical development and application of information and communication technologies and, in particular, the educational reform towards learners' competencies.

\section{References}

Barab, S., Zuiker, S., Warren, S., Hickey, D. A. N., Ingram-goble, A., Kwon, E., ... Herring, S. C. (2007). Curriculum : Relating Formalisms and Contexts. Science Education, 91, 750-782. https://doi.org/10.1002/sce

Björn, P. M., Aunola, K., \& Nurmi, J. E. (2016). Primary school text comprehension predicts mathematical word problem-solving skills in secondary school. Educational Psychology, 36(2), 362-377. https:// doi.org/10.1080/01443410.2014.992392

Boyer, C. B., \& Merzbach, U. C. (2011). A history of mathematics. John Wiley \& Sons. 
Cowan, P. (2006). Teaching mathematics: A handbook for primary and secondary school teachers. London: Routledge.

Dabbagh, N., Benson, A. D., Denham, A., Joseph, R., Al-Freih, M., Zgheib, G., ... Guo, Z. (2016). Evolution of Learning Technologies: Past, Present, and Future. In Learning Technologies and Globalization (pp. 1-7). https://doi.org/10.1007/978-3-319-229638_1

Dung, T., Duyen, N. T., An, N. T. T., Giang, N. T. N., \& Phuong, T. M. (2019). Bridging to mathematical modelling: Vietnamese students' response to different levels of authenticity in contextualized tasks. International Journal of Mathematical Education in Science and Technology, 1-20. https:// doi.org/10.1080/0020739X.2019.1648890

Gardner, H., \& Hatch, T. (1989). Multiple Intelligences Go to School: Educational Implications of the Theory of Multiple Intelligences. Educational Researcher, 18(8), 4. https://doi.org/10.2307/1176460

Hao, T. V., Hy, N. M., Doanh, N. V., \& Huyen, T. D. (2006). Geometry 10. Vietnam Education Publishing House Limited Company.

Hiebert, J., Carpenter, T. P., Fennema, E., Fuson, K., Human, P., Murray, H., ... Wearne, D. (1996). Problem solving as a basis for reform in curriculum and instruction: The case of mathematics. Educational Researcher, 25(4), 12-21. https:// doi.org/10.3102/0013189X025004012

Linh, N. Q., \& Phuong, H. (2019). STEM education in the General Education Program. TNU Journal of Science and Technology, 206(13), 111.

Ly, P. V. (2013). Enhancing problems with practical contents in teaching differential calculus, integration of variable function in pedagogical college. Journal of Science, Hanoi National Universty of Education, 58(3), 147-153.

Malmia, W., Makatita, S. H., Lisaholit, S., Azwan, A., Magfirah, I., Tinggapi, H., \& Umanailo, M. C. B. (2019). Problem-based learning as an effort to improve student learning outcomes. International Journal of Scientific and Technology Research, 8(9), 1140-1143.

Ministry of Education and Training, (2018). V, General Education Program.

Nam, N. D. (2015). Simulative capacity of mathematics of high school student. Science Magazine, Hanoi University of Pedagogy, 60(8), 44-52.

Nam, N. D. (2016). Modelling in Vietnamese School Mathematics. International Journal of Learning, Teaching and Educational Research, 15(6), 114-126.

Nghi, B. V. (2018). Some contents integrating mathematics and physics. Vietnam Journal of Education, 5(2009), 9-13.

Palinussa, A. L. (2013). Students' critical mathematical thinking skills and character: IndoMS.J.M.E, 4(1), 75-94.

Quynh, D., Cuong, V. N., Khue, P. V., \& Nghi, B. V. (2014). Geometry 10 (advanced). Vietnam Education Publishing House Limited Company.

Schubring, G. (2014). On historiography of teaching and learning mathematics. In Handbook on the history of mathematics education (pp. 3-8). https://doi.org/10.1007/978-1-4614-9155-2_1

Tam, D., \& Ngu, P. N. H. (2017). Designing and using situations in teaching Mathematics based on RME's core principles. Vietnam Journal of Education, 1, 32-36.

Tong, D. H., Loc, N. P., Uyen, B. P., \& Giang, L. T. (2019). Developing the competency of mathematical modelling: A case study of teaching the cosine and sine theorems. International Journal of Learning, Teaching and Educational Research, 18(11), 18-37. https://doi.org/10.26803/ijlter.18.11.2

Trung, N. T. (2018). Some suggestions on the application of the realistic mathematics education and the didactical situations in mathematics teaching in Vietnam. 
Journal of Science, Hanoi National Universty of Education, 9, 1-15. https:// doi.org/10.3109/08830185.2014.902452

Trung, N. T., Thao, T. T. P., Hang, N. V. T., Anh, H. N., Trung, T., Hiep, P. H., \& Nghi, B. V. (2020). Realistic Mathematics Education in Vietnam: Recent Policies and Practices. International Journal of Education and Practice, 8(1), 57-71. https://doi.org/10.18488/journal.61.2020.81.57.71

Trung, N. T., Thao, T. T. P., \& Trung, T. (2019). Realistic mathematics education (RME) and didactical situations in mathematics (DSM) in the context of education reform in Vietnam. Journal of Physics: Conference Series, 1340(1), 1-14. https://doi.org/10.1088/1742-6596/1340/1/012032

Viet, D. Q. (2013). Basic ideas contained in high school mathematics. Vietnam Education Publishing House Limited Company, Vietnam.

Vui, T. (2018). Bringing Mathematics Education into the global orbit to develop thinking, logic and creativity in solving realistic problems with closed-open approach. Vietnam Journal of Education, 5, 28-33.

Wang, Y. (2018). Research on the Application of Internet Information Technology in Higher Mathematics Classroom Teaching. In the Proceedings of the 2018 5th International Conference on Education, Management, Arts, Economics and Social Science (ICEMAESS 2018). https:// doi.org/10.2991/icemaess-18.2018.166 